\title{
a Gestão Pedagógica no Seio de Uma Instituição: O Caso Do CAUÉ - Coral Alentejano da Universidade De Évora
}

José Bravo Nico

Cristina Barrenho ${ }^{2}$

\section{Resumo:}

Da criação, em 2004, da Seç̧ão Pedagógica do Coral Alentejano da Universidade de Évora, resultou a necessidade de encontrar um quadro organizacional que articulasse a participação dos (das) estudantes Universitários (as) (coralistas ou não), com as actividades próprias de um coral e com a extensão destas às escolas básicas. Desta forma, pretende-se promover o cante alentejano como ponto de partida e de chegada, no desenho e concretização curricular de projectos educacionais. Assim sendo, surgiu a figura de Gestor Pedagógico concretizada, formalizada e legitimada através da aprovação de um projecto de Estágio Profissional, por parte do Instituto de Emprego e Formação Profissional.

A comunicação que se apresenta descreve a actividade desenvolvida, há mais de um ano, pela Gestora Pedagógica do Coral Alentejano da Universidade de Évora.

\section{Caracterizaçāo da Instituição -CauÉ- Coral Alentejano da UNIVERSIDADE DE Évora}

O CAUÉ surgiu em 1994, devido à necessidade sentida, na Universidade de Évora, de impulsionar e divulgar o cancioneiro alentejano e de estabelecer laços de amizade e de convívio entre a vida académica e o meio social em que a academia está inserida. Por iniciativa própria e em colaboração com outras entidades, ao longo do ano 2002/2003, o Coral Alentejano criou a sua Secção Pedagógica através da qual foram dinamizadas a seguintes actividades: Projecto ABZ, Projecto VISITAS DE ESTUDO e o Projecto TRUM. Simultaneamente o Coral Alentejano foi um dos parceiros na organização do I e II Encontro Regional de Educação "Aprender no Alentejo", iniciativa promovida pelo Departamento de Pedagogia e Educação da Universidade de Évora.

\section{A Gestão Pedagógica}

A Gestão Pedagógica da secção Pedagógica do Coral Alentejano segue os princípios Orientadores do Modelo de Apoio à Aprendizagem proposto por Berbaum (1992).

' Departamento de Pedagogia e Educaçâo da Universidade de Évora

${ }^{2}$ Coral Alentejano da Universidade de Évora 
A Gestão Pedagógica no Seio de uma Instituição: o caso do CAUÉE-Coral Alentejano da Universidade De Évora

Segundo Berbaum, a aprendizagem assenta em quatro vértices principais, que se representam na figura seguinte:

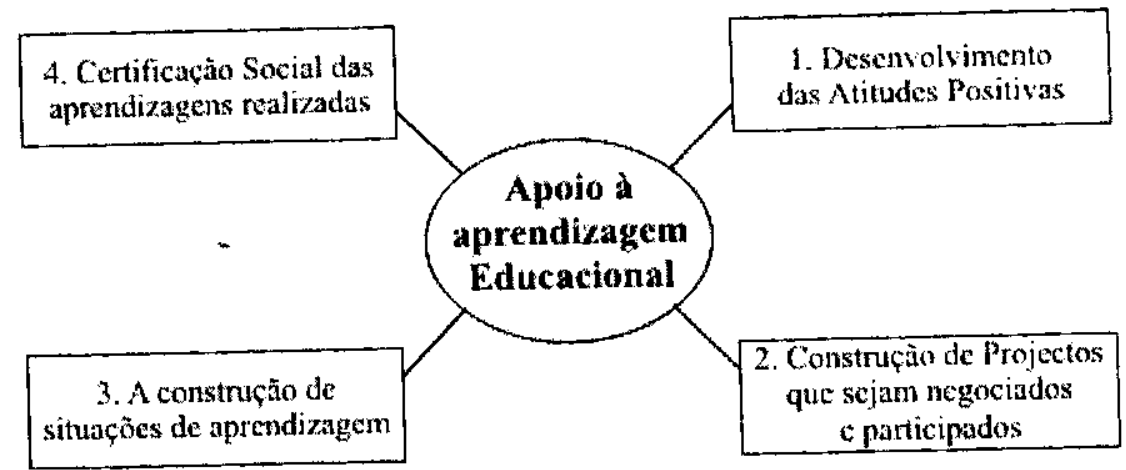

Figura 1. - O Modelo de Gestão Pedagógica (adaptado de Berbaum, 1992)

Nesta condição, a Gestão Pedagógica assumiu os seguintes objectivos:

- concepção de um Projecto integrado e coerente de âmbito educacional destinado à Secção

Pedagógica do CAUÉ;

- dinamizar e coordenar as actividades constantes do Projecto Pedagógico do CAUÉ;

- avaliar o grau de execução do Projecto.

Desta forma, as actividades desenvolvidas foram diversificadas e de natureza intergeracional, como se podem constatar no diagrama seguinte:

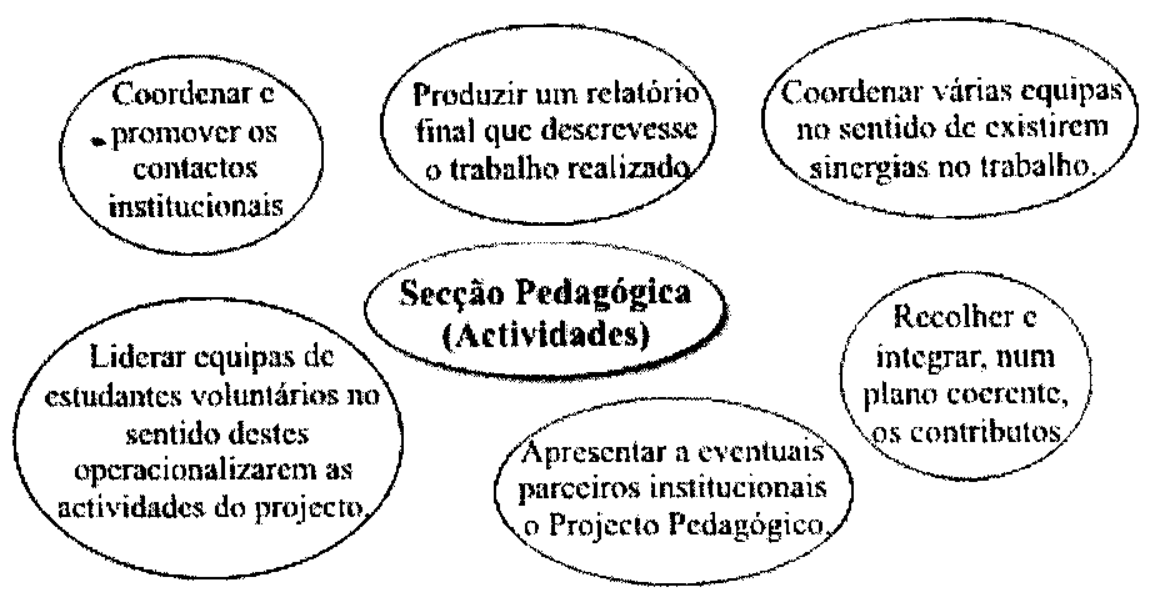

Figura 2. - Actividades da Secção Pedagógica do CAUÉ 


\section{Seç̧ão II - Ambientes Institucionais de Aprendizagem}

A Gestão Pedagógica pode contribuir para que se enquadrem e desenvolvam todas as actividades, projectos, recursos, órgãos e serviços directamente relacionados com o meio envolvente e com o processo de aprendizagem. Mas, para se desenvolver uma gestão pedagógica adequada, é necessário um bom envolvimento e uma boa articulação de todos os intervenientes, sejam eles órgãos de decisão administrativa, financeira e de gestão de espaços. Caberá a todos estes intervenientes a tarefa mais importante, a da concretização dos projectos, viabilizando condiçzes para a implementação quotidiana da missão proposta.

A Gestâa Pedagógica, corresponde às seguintes aç̧ôes:

- Apoiar ou potenciar actos pedagógicos, estimulando vocações dos percursos humanos; potenciando embriões de projectos pedagógicos; enquadrando recursos humanos e projectos pedagógicos.

- Accionar órgãos de Gestão Pedagógica e órgãos de apoio, promovendo participação efectiva de todos os órgãos; responsabilizando os órgãos pelas suas actividades/atribuições e ou competências, promover interacção de competências.

Conceber e Implementar Projectos Educativos, listando projectos pedagógicos, intervenientes, recursos e calendarização; elaborando projectos educativos e planos de actividades; estabelecendo regulamentos e avaliando a implementação do Projecto Pedagógico.

O presente projecto de Gestão Pedagógica que tem vindo a ser implementado no Coral Alentejano da Universidade de Évora tem também, por outro lado, para o processo de integração dos estudantes caloiros na Universidade de Évora, particularmente do Curso de Licenciatura em Ensino Básico.

Os projectos ABZ, TRUM e VISITAS DE ESTUDO envolveram a participação de alguns estudantes de primeiro ano, facto que possibilitou uma determinada infusão profissional, em simultâneo com a participação nas actividades académicas de natureza mais cultural. Em paralelo, o contacto com o cancioneiro alentejano impregnava toda esta actividade estudantil, dando assim corpo a uma perfeita simbiose entre a cultura académica, a cultura local e a cultura do próprio curso de pertença.

\section{REFERÉnCIAS BibliográficAs}

BARBIER, J. (1996), Elaboração de Projectos de Acção e_planificação, Porto: Porto Editora.

BERBAUM, J.(1992), Desenvolver a Capacidade de Aprendizagem, Lisboa: Edições Escola Superior de Educação João de Deus 
A Gestão Pedagógica no Seio de uma Instituição: o caso do CAUÉ - Coral Alentejano da Universidade De Évora

BRITO, C. (1991), Gestão Escolar Participada-Na Escola todos somos Gestores; $1^{\text {a }}$ edição, Lisboa: Texto Editora

COSTA, J. (1996), Gestão Escolar-Participação, Autonomia, Projecto Educativo da Escola, $4^{\text {a }}$ edição, Lisboa: Texto Editora

GOLEMAN, D.; BOYATZIS, R. \& MCKEE, A. (2002), Os_novos Lideres - A Inteligência Emocional nas Organizações, .. ${ }^{a}{ }^{\mathrm{a}}$ edição, Lisboa: Gradiva 